\title{
COVID-19 and anosmia: A case control study in Mirpur, Azad Jammu and Kashmir Pakistan.
}

1. MBBS, M.Phil

Professor Pathology

MBBS-MC Mirpur AJK

2. MBBS, DLO, FCPS

Associate Professor ENT

MBBS-MC Mirpur AJK.

3. MBBS, M.Phil

Assistant Professor Pathology

MBBS-MC Mirpur AJK.

4. MBBS, M.Phil

Senior Lecturer Pathology

DHQ-TH Mirpur AJK.

5. MBBS, FCPS

Assistant Professor ENT

DHQ-TH Mirpur AJK

6. MBBS, FCPS

Pathologist

$\mathrm{CMH}$ Bahawalpur.

Correspondence Address:

Dr. Syed Manzoor lqbal

Department of Pathology

MBBS-MC Mirpur AJK.

dr_manzoor@hotmail.com

Article received on:

03/10/2020

Accepted for publication:

$12 / 02 / 2021$

\begin{abstract}
Syed Manzoor Iqbal ${ }^{1}$, Faisal Bashir ${ }^{2}$, M. Kaleem ${ }^{3}$, Sidra Aslam ${ }^{4}$ Ejaz Ahmed ${ }^{5}$, M. Aurang Zeb ${ }^{6}$
\end{abstract}
ABSTRACT... Objective: The study aims to find the symptoms of COVID-19 in the population of Azad Jammu and Kashmir, Pakistan. It will then correlate the symptoms observed to the COVID-19 patients based on their day of monitoring. Study Design: Case-control study. Setting: Hospitals of Mirpur, Azad Jammu and Kashmir. Period: April 2019 to Dec 2020. Material \& Methods: It was carried out in order to estimate the patients of COVID-19 with the symptoms of anosmia. Patients visiting the hospitals in the vicinity of Mirpur, Azad Jammu and Kashmir for their COVID-19 related symptoms were included in the study Sampling of the patients was done in the DHQT-H, Mirpur for the patients visiting the hospital and also from those who were isolated in Mohiuddin Islamic Medical college isolation ward. Demographic data was obtained. Day of PCR testing and their results were recorded for further statistical analysis of the prevailing symptoms in the population. Results: Most of the male population visited the hospitals with most COVID positive results and prevalence of anosmia within age group of 30-45 years. The affected regions were mostly Bhimbar and Mirpur. Conclusion: A high prevalence of COVID-19 symptoms particularly anosmia was observed in the middle-aged population of Mirpur, Azad Jammu and Kashmir.

Key words: $\quad$ Coronavirus, COVID-19, Anosmia, Symptoms, Smell, Taste.

Article Citation: lqbal SM, Bashir F, Kaleem M, Aslam S, Ahmed E, Aurang Zeb M. COVID-19 and anosmia: A case control study in Mirpur, Azad Jammu and Kashmir Pakistan. Professional Med J 2021; 28(6):772-778.

https://doi.org/10.29309/TPMJ/2021.28.06.6125

\section{INTRODUCTION}

The quick spread of severe acute respiratory syndrome Coronavirus 2 (SARS-CoV-2) has enabled researchers around the world to obtain a large amount of clinical data on Coronavirus Disease (COVID-19). ${ }^{1}$ Severe health emergencies are making data collection and analysis extremely difficult, but some important clinical differences are starting to emerge between the Chinese and European case series. The clinical description of the 2019 coronavirus disease (COVID-19) outbreak in China shows that most patients (81\%) have influenza-like illness (ILI) or mild pneumonia ${ }^{2}$, while $19 \%$ of cases have acute or severe pneumonia. Fever, cough, fatigue and muscle pain are usually the main symptoms. The expression of COVID-19 ILI seems uncertain. No thoughts of exposure, no specific symptoms that can lead to suspicion of the disease. ${ }^{3}$
Post-virus loss of smell is one of the main causes of loss of smell in adults, accounting for up to $40 \%$ of cases of anosmia. Viruses that cause the common cold are known to cause gastric loss, and more than 200 different viruses are known to cause upper respiratory infections. ${ }^{4}$ Coronaviruses previously described are thought to be responsible for $10-15 \%$ of cases. It has been proven that human strains of the Coronavirus invade the central nervous system through the nerve epithelium and spread from within the olfactory bulb. After clinical examination of the first patient, it was observed that several cases reported anosmia. ${ }^{5}$ Rarely, COVID-19 may describe a loss of sense of smell and other ENT symptoms. For example, ENT doctors' recent comments on COVID-19 confirmed that otolaryngology symptoms are not common in COVID-19 because nasal congestion and runny nose have been observed in less than $5 \%$ of 
cases. $^{6}$

Therefore, it is not surprising that the new COVID-19 virus may also cause anosmia in infected patients. More and more non-peerreviewed evidence shows that a large number of patients infected with COVID 19 have developed anosmia / hyposmia. In Germany, a study reported in the media showed that even though the time of onset was not asked, more than two-thirds of people still confirmed loss of smell and taste. ${ }^{7}$ In addition, more and more anecdotal reports indicate that the number of patients with olfactory abnormalities with mild or no other symptoms has increased significantly-surgeons from the medical community shared this widely in medical seminars. ${ }^{8}$ The incidence of COVID-19 cases is high in all regions. In a study of 3191 COVID-19 patients who had a mild illness at home and selfisolated, $15.3 \%$ of them reported loss of smell or taste. ${ }^{9}$

It is reported that anosmia (loss of smell) and dysgeusia (altered taste) are associated with the COVID-19 pandemic. Anosmia may be related to loss of smell, leading to changes in taste. Published and unpublished anecdotal reports about COVID-19-related anosmia in various parts of the world (including South Korea, Germany, Italy, the United Kingdom, Iran, and the United States). In South Korea, an informal telephone survey conducted by the Daegu City Council found that of the 3191 confirmed SARS-CoV-2 cases, 15.3\% had anosmia or dysgeusia. German virologist, Hendrick Streeck reported that in 100 patients, more than two-thirds of the sense of smell and taste were lost. Those interviewed by an Italian infectious disease expert from the University of Milan pointed out that the symptoms were mild or severe. ${ }^{10,11}$ Limited patients seem to experience anosmia and dysgeusia; however, these appear to appear later in the infection process. A nonpeer-reviewed Iranian study conducted a study on 10,069 patients with anosmia or hypotonic (COVID-19 status unknown) and found that $76.2 \%$ of them had sudden onset of symptoms. ${ }^{12}$

Currently, neither the World Health Organization nor the Centers for Disease Control and
Prevention consider anaerobic disease as a screening symptom. As we continue to treat this pandemic, it is critical to identify symptoms other than the typical triad of fever, cough, and dyspnea to facilitate the timely identification of infected individuals who may spread the virus without knowing it. The characteristic symptoms including anosmia can be used to guide early and extensive testing to alleviate the disease. ${ }^{13}$

The study aims to find the symptoms of COVID-19 in the population of Mirpur division, Azad Jammu and Kashmir, Pakistan and correlate the symptoms observed respect to their age.

\section{MATERIAL \& METHODS}

The following study was conducted in order to evaluate the prevalence of COVID-19 in the people of Mirpur, Azad Jammu and Kashmir particularly focusing on the symptoms that are observed during the illness. Anosmia being one of the most common symptoms observed while infected with SARS-CoV-2, was highlighted among the patients having positive and negative tests for COVID-19. The age of the patients and the time for PCR test done to confirm the illness were also considered to correlate the effect of illness on the patients of different age groups.

A cross sectional study was conducted in the locality of Mirpur Division of Azad Jammu and Kashmir, Pakistan. Sampling was done in three district Mirpur, Bhimber and Kotli. District health office took sample from general population of the three districts while DHQ Hospital Bhimber and Kotli took the sample from the patients visiting to hospital. DHQ Hospital, Mirpur have RT-PCR facility whereas, an isolation ward was maintained at Mohiuddin Islamic Medical College isolation ward. For the confirmation of the disease, RT-PCR testing was carried out in a laboratory located in DHQT-H Mirpur. Frequency distribution of the demographics were calculated. t-test was applied for the calculation of $p$-values using statistical software such as IBM SPSS Statistics 25.

\section{RESULTS}

The frequency distribution of the patients' age is depicted in the figure below. 


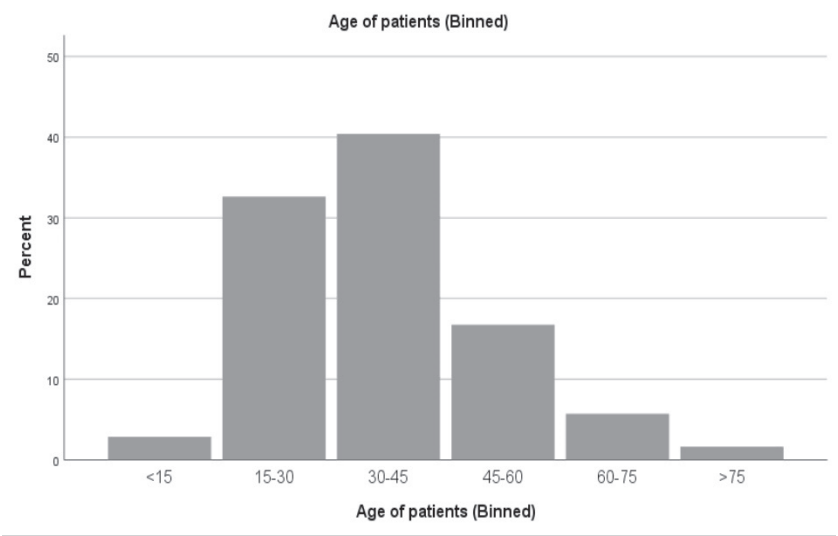

Figure-1. Age distribution of COVID-19 patients

The gender of patients Tested for their symptoms are summarized in the figure below. Among the patients, 74.4 percent were male and 25.6 percent were female.

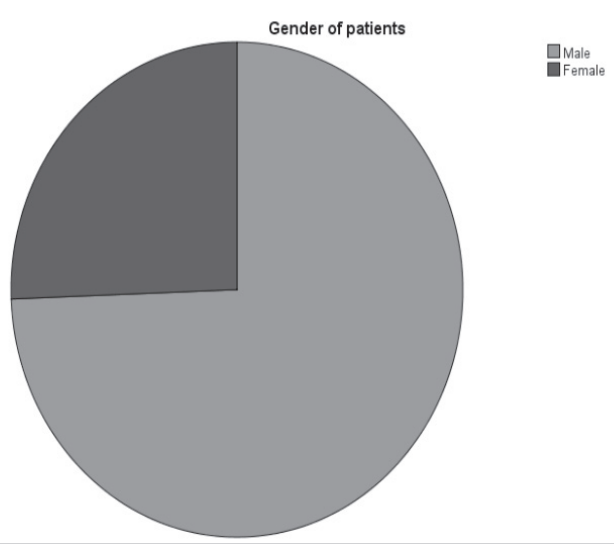

Figure-2. Gender distribution of patients.

In the region of Mirpur division Azad Jammu and Kashmir, the patients reported with COVID-19 symptoms are listed below in table. Maximum patients were observed from Bhimber and Mirpur.

\begin{tabular}{|l|c|}
\hline & Frequency (\%) \\
\hline Bhimber & $100(40.0$ \\
\hline DHO Bhimber & $9(3.6$ \\
\hline DHQ Mirpur & $33(13.2$ \\
\hline Gujrat & $1(.4$ \\
\hline Kort & $1(.4$ \\
\hline MIMC & $13(5.2$ \\
\hline Mirpur & $88(35.2$ \\
\hline Muzaffarabad & $2(.8$ \\
\hline NCTH & $1(.4$ \\
\hline Pallandari & $2(.8$ \\
\hline Total & $250(100.0$ \\
\hline
\end{tabular}

Table-I. Frequency distribution of patients in different regions of Mirpur, Azad Jammu and Kashmir.

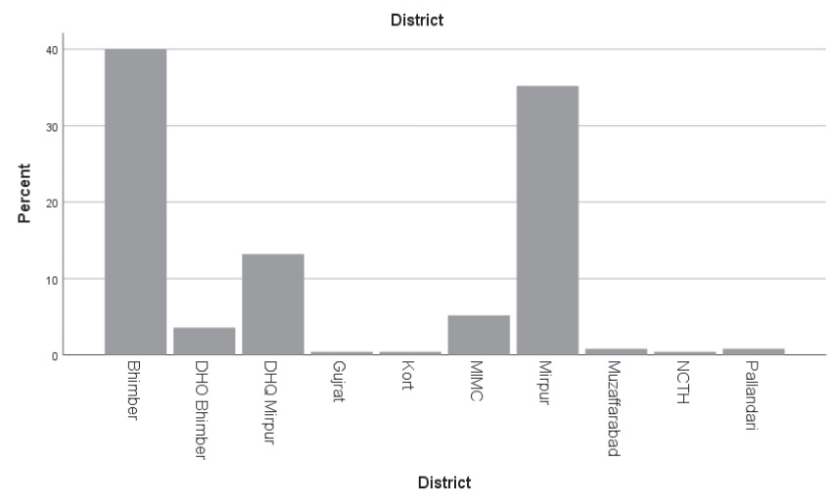

Figure-3. Frequency distribution of COVID-19 patients with respect to area.

Day of testing for COVID-19, test remarks for PCR testing and prevailing symptoms of anosmia

Over a span of 45 days, the tests done repeatedly for the patients are charted below in Figure-4.

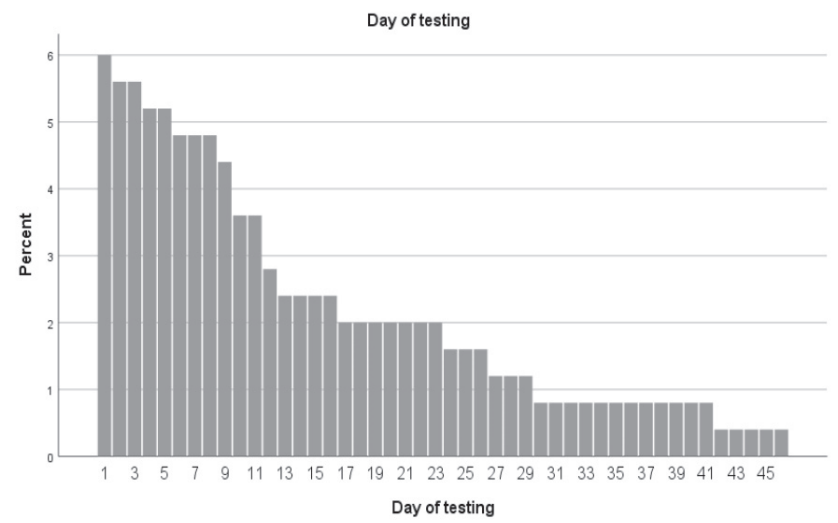

Figure-4. Day of testing for COVID-19 patients

Results of symptomatic patients gone through PCR testing for the confirmation of COVID-19 are shown in the figure below. Among these, 211 patients $(84.4 \%)$ were presented with a negative result, 37 patients $(14.8 \%)$ had a positive result whereas, 2 of them (0.8\%) were asked for repeating the test.

The symptoms of anosmia were observed in the patients visiting the hospital and were found to be $18.8 \%$ (47 in number) with the symptoms of anosmia and $81.2 \%$ (203 in number) with no symptoms of anosmia. 

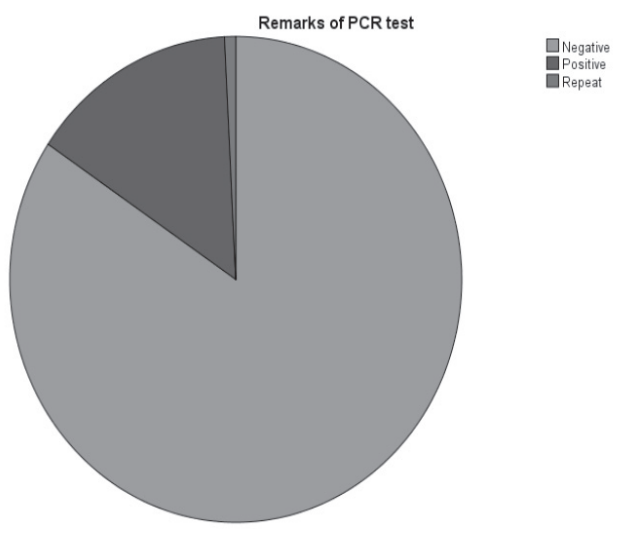

Figure-5. Remarks of PCR test

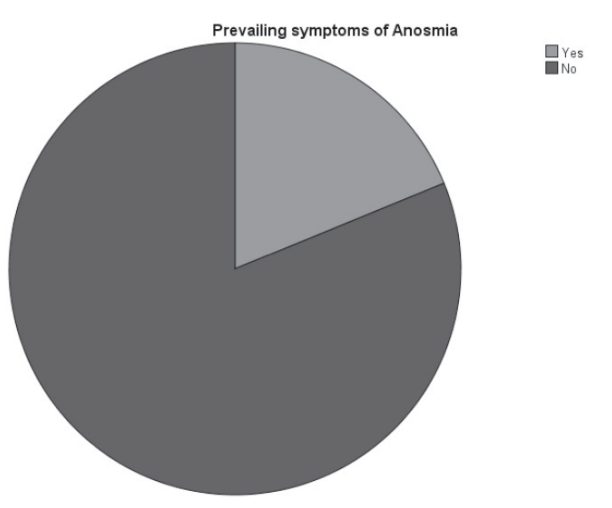

Figure-6. Prevailing symptoms of anosmia in COVID-19 patients

\section{Correlation of PCR test with age}

The correlation of patients age and the results of PCR test are tabulated below and the results are displayed in Figure-7.

\begin{tabular}{|c|c|c|c|c|c|}
\hline & & \multicolumn{3}{|c|}{ Remarks of PCR Test } & \multirow{3}{*}{$\begin{array}{c}\begin{array}{c}\text { P- } \\
\text { Value }\end{array} \\
0.029\end{array}$} \\
\hline & & Negative & Positive & Repeat & \\
\hline \multirow{6}{*}{$\begin{array}{l}\text { Age of } \\
\text { patients } \\
\text { (Binned) }\end{array}$} & $<15$ & 6 & 1 & 0 & \\
\hline & $15-30$ & 67 & 12 & 1 & 0.0004 \\
\hline & $30-45$ & 82 & 17 & 0 & 0.0001 \\
\hline & $45-60$ & 38 & 3 & 0 & 0.0004 \\
\hline & $60-75$ & 12 & 2 & 0 & 0.004 \\
\hline & $>75$ & 2 & 2 & 0 & 1 \\
\hline \multicolumn{2}{|l|}{ Total } & 207 & 37 & 1 & \\
\hline Table- & Corre & $\begin{array}{r}\text { ion of pa } \\
\text { PCR } t\end{array}$ & $\begin{array}{l}\text { tints' age } \\
\text { ting. }\end{array}$ & and reme & rks of \\
\hline
\end{tabular}

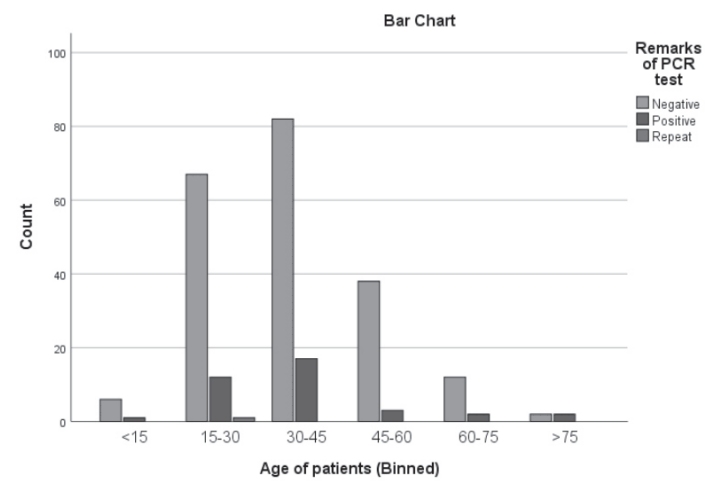

Figure-7. Correlation of patients' age and remarks of PCR testing

Correlation of prevailing symptoms with respect to age

\begin{tabular}{|c|c|c|c|c|}
\hline & \multicolumn{2}{|c|}{$\begin{array}{l}\text { Prevailing } \\
\text { Symptoms of } \\
\text { Anosmia }\end{array}$} & \multirow{3}{*}{$\begin{array}{c}\text { P-Value } \\
1\end{array}$} \\
\hline & & Yes & No & \\
\hline \multirow{6}{*}{$\begin{array}{l}\text { Age of } \\
\text { patients } \\
\text { (Binned) }\end{array}$} & $<15$ & 3 & 4 & \\
\hline & $15-30$ & 13 & 67 & 0.00017 \\
\hline & $30-45$ & 21 & 78 & 0.00016 \\
\hline & $45-60$ & 6 & 35 & 0.00063 \\
\hline & $60-75$ & 3 & 11 & 0.0077 \\
\hline & $>75$ & 0 & 4 & 0.05 \\
\hline \multicolumn{2}{|l|}{ Total } & 46 & 199 & \\
\hline
\end{tabular}

Table-III. Prevailing symptoms of anosmia corresponding to age.

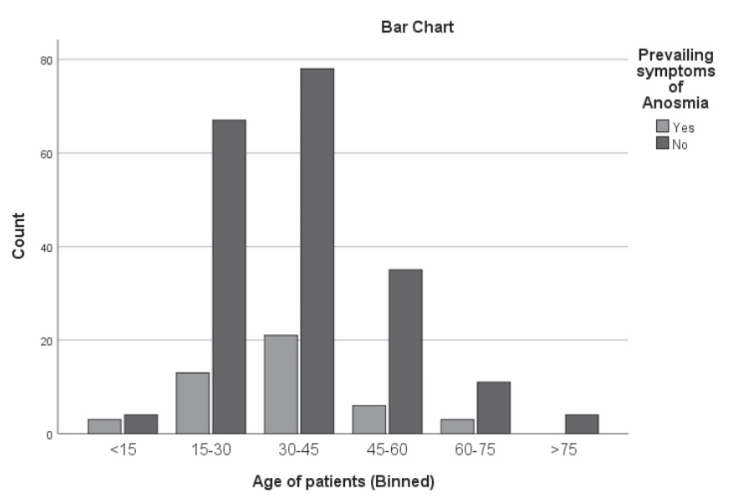

Figure-8

\section{DISCUSSION}

It is estimated that the prevalence of severe anosmia in population studies is about $18 \%$. $^{13,14}$ The risk factors are increasing age and male sex; the incidence of olfactory function in males before the age of $30-45$ is generally increased 
significantly and may reduce with time. ${ }^{14,15}$ This also usually reports a higher rate of olfactory loss. In our study, only a small percentage are over 70 years old, which also indicates that there is an increase chance of the prevalence of anosmia that already exists in this age group. According to reports, in the elderly with more severe symptoms, anosmia caused by the emphasis on respiratory care has been ignored. The obvious male advantage needs further research, as it may only reflect gender differences in the patients that visit hospitals for their symptoms.

Viral sequelae are a common cause of loss of smell, and it is reported that temporary loss may be short-lived, so the true incidence is unclear. ${ }^{16}$ The apparent increase in incidence may only reflect that COVID-19 has attracted media attention, and this situation may be caused by unrelated rhinovirus and coronavirus strains that have never been reported before. However, more and more anecdotal evidence supports the COVID-19 infection. In recent weeks, searches on the Internet for loss of smell and visits to patient support groups have increased significantly. ${ }^{17}$ Any previous reports on social media or possible links between anosmia and COVID-19 infection have preceded this. ${ }^{18}$ It is worth noting that the increase in search volume occurred in developed countries and the increase in users in the Pakistan is similar. In the peer-reviewed literature, a small number of case series appear. Giacomelli et al. interviewed 59 hospitalized COVID-19 patients and found that $34 \%$ reported having smell or taste disorders. ${ }^{19}$ Although most of our study samples does meet the current testing standards used internationally because it is only performed in hospitalized patients, only $14.8 \%$ of the test results in our survey were positive. Although we do not know the test method, in most cases. In this case, RT-PCR analysis of oro-pharyngeal and naso-pharyngeal was used, with an estimated sensitivity of $72 \% .^{20}$

Patients who have developed anosmia without any other symptoms were not suspected of having COVID-19 before, and may be some carriers hidden so far, which promote the rapid spread of infection. According to current guidelines, must observe self-quarantine if they show any of the symptoms associated with COVID-19 along with a positive result. Therefore, new paroxysmal anosmia (in the absence of a recent head injury or severe nasal congestion) may be used as a screening tool to help identify asymptomatic patients who continue to be a vector, which can then be better guided. Overall, in multiple studies conducted around the globe, nearly a quarter of respondents reported hypoxia as a simple symptom or the first symptom. ${ }^{21}$

Perhaps more importantly, it can be used as a tool for testing first-line medical staff to prevent the spread of disease in hospitals. An Italian colleague reported anecdotally an extremely high incidence of anosmia in the frontline health care work (personal communication). The first author's direct colleague reported anosmia 72 hours ago and the result was positive. ${ }^{22} \mathrm{He}$ then self-isolated; testing reduced the risk of medical staff and patients who might have been in contact. In addition, it must be considered an important incentive for medical staff to make full use of PPE and avoid nasal endoscopy to help cope with the higher infection rate of ENT surgeons compared to other medical staff.

\section{LIMITATIONS}

The major limitation of this study is the limited number of confirmed COVID-19 status, as discussed above. However, as testing is currently restricted to only those hospitalized in the Azad Jammu and Kashmir, the facilities are largely ineligible for testing. While the observation was initially made on the patients making contact for advice on new onset anosmia, the observation can be widely disseminated beyond this initial population. Lack of objective testing facilities or review of medical records was present. We cannot estimate the overall prevalence of anosmia in those infected with COVID-19, however unless widespread testing in the community is undertaken, any study in those hospitalized is also prone to selection bias in evaluating a more severely affected, and likely older population. The benefit of this study is that it may offer a picture of patients who would likely be missed by current diagnostic criteria, selected populations 
with severe disease requiring hospitalization or targeted testing regimens.

\section{CONCLUSION}

Although formal research is needed to determine the incidence of anosmia in patients with COVID-19 and more extensive testing of patients with new-onset anosmia, this is the first to record the clinical manifestations of patients with anosmia in the pre-pandemic period within the vicinity of Mirpur, Azad Jammu and Kashmir. A formal test for COVID-19 is conducted and can be used to help design future research. Such research may include objective testing of odor and taste to better define the subjective report described herein.

\section{CONFLICT OF INTEREST}

This study has no conflict of interest to be declared by any author.

Copyright@ 12 Feb, 2021.

\section{REFERENCES}

1. Andersen KG, Rambaut A, Lipkin WI, Holmes EC, Garry RF. The proximal origin of SARS-CoV-2. Nature medicine. 2020 Apr; 26(4):450-2.

2. Wang D, Hu B, Hu C, Zhu F, Liu X, Zhang J, Wang B, Xiang $\mathrm{H}$, Cheng $\mathrm{Z}$, Xiong $\mathrm{Y}$, Zhao Y. Clinical characteristics of 138 hospitalized patients with 2019 novel coronavirus-infected pneumonia in Wuhan, China. Jama. 2020 Mar 17; 323(11):1061-9.

3. Gane SB, Kelly C, Hopkins C. Isolated sudden onset anosmia in COVID-19 infection. A novel syndrome. Rhinology. 2020 Apr 2;10.

4. Brann D, Tsukahara T, Weinreb C, Logan DW, Datta SR. Non-neural expression of SARS-CoV-2 entry genes in the olfactory epithelium suggests mechanisms underlying anosmia in COVID-19 patients. Bio Rxiv. 2020 Jan 1.

5. Galougahi MK, Ghorbani J, Bakhshayeshkaram M, Naeini AS, Haseli S. Olfactory bulb magnetic resonance imaging in SARS-CoV-2-induced anosmia: The first report. Academic Radiology. 2020 Apr 11.

6. Patel A, Charani E, Ariyanayagam D, Abdulaal A, Denny SJ, Mughal N, Moore LS. New onset anosmia and ageusia in adult patients diagnosed with SARSCoV-2. Clinical Microbiology and Infection. 2020 Jun 2.
7. Hopkins C, Surda P, Whitehead E, Kumar BN. Early recovery following new onset anosmia during the COVID-19 pandemic-an observational cohort study. Journal of Otolaryngology-Head \& Neck Surgery. 2020 Dec; 49:1-6.

8. Russell B, Moss C, Rigg A, Hopkins C, Papa S, Van Hemelrijck M. Anosmia and ageusia are emerging as symptoms in patients with COVID-19: What does the current evidence say?. E cancer medical science. 2020;14.

9. Hopkins C, Surda P, Kumar N. Presentation of new onset anosmia during the COVID-19 pandemic. Rhinology. 2020 Apr 11;10.

10. Brodwin E. Doctors warn an inability to smell could be a symptom of Covid-19-but caution the evidence is preliminary. Stat. 2020 Mar 23.

11. Stone J. There's an unexpected loss of smell and taste in coronavirus patients. Forbes. 2020 Mar 20.

12. Bagheri $\mathrm{SH}$, Asghari $\mathrm{AM}$, Farhadi $M$, Shamshiri $\mathrm{AR}$, Kabir A, Kamrava SK, Jalessi M, Mohebbi A, Alizadeh R, Honarmand AA, Ghalehbaghi B. Coincidence of COVID-19 epidemic and olfactory dysfunction outbreak. Medrxiv. 2020 Jan 1.

13. Kaye R, Chang CD, Kazahaya K, Brereton J, Denneny III JC. COVID-19 anosmia reporting tool: Initial findings. Otolaryngology-Head and Neck Surgery. $2020 \mathrm{Apr}$ 28:0194599820922992.

14. Brämerson A, Johansson L, Ek L, Nordin S, Bende M. Prevalence of olfactory dysfunction: The Skövde population $\square$ based study. The Laryngoscope. 2004 Apr; 114(4):733-7.

15. Stogbauer J, Wirkner K, Engel C, Moebus S, Pundt N, Teismann H, Loffler M, Hummel T, Beule AG, Berger K. Prevalence and risk factors of smell dysfunction-a comparison between five German population-based studies. Rhinology. 2020 Apr 1; 58(2):184-91.

16. Wang X, Zhang C, Xia X, Yang Y, Zhou C. Effect of gender on odor identification at different life stages: A meta-analysis. Rhinology. 2019 Jan 1; 57(5):322-30.

17. Vaira LA, Salzano G, Deiana G, De Riu G. In response to anosmia and ageusia: Common findings in COVID-19 patients. The Laryngoscope. 2020 Jul 16.

18. Gane SB, Kelly C, Hopkins C. Isolated sudden onset anosmia in COVID-19 infection. A novel syndrome. Rhinology. 2020 Apr 2;10. 
19. Giacomelli A, Pezzati L, Conti F, Bernacchia D, Siano M, Oreni L. Self-reported olfactory and taste disorders in SARS-CoV-2 patients: A cross-sectional study [published online ahead of print March 26, 2020]. Clin Infect Dis. https://doi. org/10.1093/cid/ciaa330.

20. Yang W, Yan F. Patients with RT-PCR-confirmed COVID-19 and normal chest CT. Radiology. 2020 May; 295(2):E3-.
21. Bodas M, Peleg K. Self-Isolation compliance in the COVID-19 Era influenced by compensation: Findings from a recent survey in Israel: Public attitudes toward the COVID-19 outbreak and self-isolation: A cross sectional study of the adult population of Israel. Health Affairs. 2020 Jun 1; 39(6):936-41.

22. Foley JA, Chan E, Van Harskamp N, Cipolotti $\square$ L. A: worldwide have died with Covid-19 coronavirus. Since the first.

\begin{tabular}{|c|l|l|l|}
\hline \multicolumn{3}{|c|}{ AUTHORSHIP AND CONTRIBUTION DECLARATION } \\
\hline Sr. \# & \multicolumn{1}{|c|}{ Author(s) Full Name } & \multicolumn{1}{|c|}{ Contribution to the paper } & Author(s) Signature \\
\hline 1 & Syed Manzoor lqbal & $\begin{array}{l}\text { Direct / sample processing \& } \\
\text { diagnosis. } \\
\text { Direct / evaluation. }\end{array}$ \\
\hline 3 & Faisal Bashir & Indurect / sample processing. \\
\hline 5 & Sidra Aslam & Indurect / sample processing. & \\
\hline 5 & Ejaz Ahmed & Indurect / Evaluation. \\
\hline
\end{tabular}

